\title{
Del libro y de los vericuetos de la lectura
}

\section{About the Book and the Twist-and-Turns of Reading}

Sobre o livro e o caminho tortuoso da leitura

José Luis Díaz-Naranjo

Académico

Sede Regional Brunca

Universidad Nacional

Costa Rica

Recibido: 15/08/2017 Aceptado: 3/3/2018

¿Qué bellos son los países aún no vistos, qué bello es el día aún no vivido, qué bello es el intenso presentimiento del mañana!

Víctor Sklovski, La cuerda del arco, 1975:p. 12

Nuestra memoria es nuestra coherencia, nuestra razón, nuestra acción, nuestro sentimiento. Sin ella no somos nada. Luis Buñuel, Mi último suspiro, 1982: p. 14.

Entre leer y jugar había muchos puentes trazados por la imaginación y que nos conducían a los países movibles que inventa el deseo.

Octavio Paz, También soy escritura. 2014, p 21.

Sólo siendo un irredimible optimista se puede persistir en la profesión de escritor en estos tiempos de penuria espiritual. Marco Tulio Aguilera Garramuño, Poéticas y obsesiones, 2010: p. 105

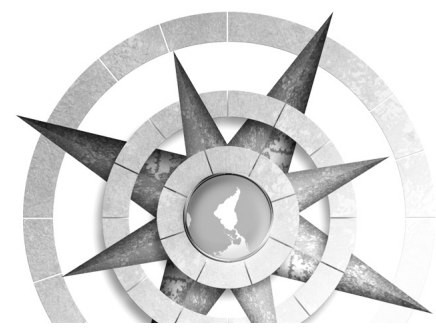


En la expresión de Borges (1983: 13), el libro es extensión de la memoria y de la imaginación. Instrumento asombroso, como lo es en alusión al cuerpo, la espada con respecto al brazo o el telescopio para el ojo, sin terminar con todas las posibles extensiones.

El libro: ¿objeto o sujeto? No soy yo sino él quien me elige, debería estar ubicado en un lugar de privilegio en el sistema cultural, cualquiera del que se trate.

Las siguientes líneas son a propósito del 23 de abril, día de San Jorge, el gran luchador contra los dragones, matador del dragón asolador de Selena, defensor de la princesa Cleodolinda, patrón de jinetes, caballeros y campesinos. Día además de la rosa y del libro. También estas líneas lo son en una clara alusión a una vivencia particular, la lectura como disciplina personal, como señalaría Proust (1999) en su hermoso texto Sobre la lectura: "[...] la más noble de las distracciones". (Proust, 2012: 95).

En mi caso particular, la búsqueda en la memoria de este encuentro con el libro, la primigenia aproximación a este objeto-sujeto, me lleva a la infancia, "Allá en otros tiempos (y buenos tiempos que eran), había una vez una vaquita (;mu! Que iba por un caminito. Y esta vaquita que iba por un caminito se encontró a un niñín muy guapin, al cual llamaban nene de la casa...". (Joyce, 1980, p. 7). Este encuentro se me presentó como un acontecer casi existencial, rodeado de todas las posibilidades naturales en cuanto a un sistema integrado y completo. "[...] un lector depende de las opciones que le proporciona la historia general de la literatura, pero cada lector, a su vez, condiciona esa historia a su historia personal" (Block de Behar, 1984: 62). No dependía en ese momento de contexto alguno con la presencia del libro; otros eran los medios para la experimentación, para el encantamiento, magia al fin. Vida en esa época por demás rústica, con la agricultura como centro sobre el que giraban todas las actividades cotidianas, libertad de exploración casi plena, faenas de diversa índole, cíclicas, llenas de experiencias vernáculas. El proceso de acercamiento fue sin precedentes, único en su género.

Esta experiencia fue un evento marcador, punto de ruptura, llegada y partida. Al decir de Barthes, (1978) la lectura provoca respuestas, aún cuando no las obtengamos en esta.

El libro, fuente de felicidad. Pessoa (1984) lo confiesa: "No conozco un placer como el de los libros [...]". (p. 41). Eco de Montaigne en la escritura, Borges (1983: 23) lo reafirma:

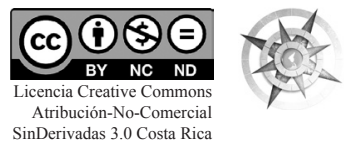


"[...] porque ve en la lectura una forma de felicidad".

La escritura es permanencia, memoria e imaginación, la visión de los antiguos: sucedánea de la palabra oral, alada y liviana, de fácil vuelo. Fuente de rebeldía. Evocación de San Anselmo, los peligros de la lectura por la ignorancia del lector, una espada en las manos de un niño. Cuando el libro llega a Oriente se le catapulta como sagrado: el Corán y la Biblia. En América, el Popol-Vuh, el Chilam Balam.

Para Dostoievski, el Quijote era un libro sagrado, Sklovski aclara, por "[...] la fe de Sancho Panza en los desvaríos de su señor" (1975: 13). Los grandes oradores mostraron su preferencia por la vivencia en contra de la escritura, vivir en el pensamiento de sus discípulos: Pitágoras no escribió por voluntad propia; Platón multiplica los personajes en sus diálogos, sigue pensando en la eternidad de Sócrates. Oralidad y escritura, por ausencia de lectores expresión de lo último: la biblioteca, la actual, espacio inerte por la ausencia de lectores (Manguel, 2013). Las bibliotecas en Emerson, espacios mágicos; se abre el libro y la función empieza.

En un mundo superficial naufraga una pedagogía de la lectura. La globalización más allá de la televisión, nos llena de sus desfiles de moda y escándalos de segundos, época de lo fútil y fugaz, liviandad a toda prueba, fábrica del aburrimiento, "[...] el aburrimiento no es simple" (Barthes, 1978: 36). Los tedios: formas de vida, sello del sedentarismo cultural. El golpe de una noticia sensacionalista no debe ser certero, se debe mojar la pólvora para que no ocurra la detonación; transcurrido el día calendario, deja de existir, habrá nuevas fuentes productoras de más morbo. "La trivialidad que nos invade, la omnipotencia y ubicuidad de la imagen y de los medios de comunicación de masas, cuya censura comercial resulta más eficaz y mortífera que la vieja censura ideológica, religiosa o política. (Goytisolo, 2006, p 12). Su vida es efímera, al igual que los artefactos de uso cotidiano producto de las fábricas en la era post industrial. Una vida útil prolongada es mal negocio. Maniqueísmo comercial.

El consumismo es y será amenaza y chantaje para el libro, en la pluma de Zaid: "[...] se supone que el comercio es sucio, o al menos poco noble" (1966: 41). La letra impresa necesita compradores, el negocio de cada día bajo el argumento simplificado de la información. Dice el comerciante, con su disfraz de político, "fuente de democratización, derecho a la

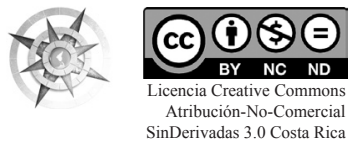

Del libro y de los vericuetos de la lectura 135 José Luis Díaz-Naranjo 
información, libertad de elegir, expresión de la voluntad".

El texto, como antagonismo, produce placer, "Es evidente que el placer del texto es escandaloso no por inmoral sino porque es atópico", señala Barthes (1978: 33). El desasosiego de Pessoa. ¡He aquí los peligros de la lectura! Relación en una doble dirección entre lectura y cultura en una operación biunívoca, casi matemática. Otro escritor, Sábato, en dialogo abierto y franco con Borges, habla sobre los diarios (Borges y Sábato, 1982)::

"Sábato: [...] La noticia cotidiana en general se la lleva el viento. Lo más nuevo que hay es el diario, y lo más viejo, al día siguiente. / Borges: Claro. Nadie piensa que deba recordarse lo que está escrito en un diario. Un diario, digo, se escribe para el olvido, deliberadamente para el olvido. / Sábato: Sería mejor publicar un periódico cada año, o cada siglo. $O$ cuando sucede algo verdaderamente importante. [...]. / Borges: (sonriendo) sí ... creo que sí. (p. 15).

Seamos más radicales en asuntos de inclusión; con todos los demás medios de comunicación debería pasar lo mismo. Así se realzaría la ocurrencia de eventos únicos: "Cristóbal Colón descubrió esta tierra que por un equívoco llamaron América", "Ezra Pound (1971) y James Joyce se retan a duelo, cada uno lanzará al otro los libros no vendidos de su propia creación", "El hombre llegó a la luna", "Muere el autor del Quijote", "Una vez más la casa de Malcolm Lowry ardió y con ella sus manuscritos", "Marco Tulio Aguilera Garramuño visitó San Isidro de El General, después de treinta y tantos años de ausencia”. Lo trascendente no faltaría con la esencia propia de lo exclusivo y la unicidad.

Lectores y escritores, sociedad dual. Autor y lector deben vivir en complicidad, afinidad de procedimientos, resultados similares, responsabilidad compartida. Block de Behar lo apunta: el lector es e-lector en tanto lee y se-lector, "[...] porque elige por sí mismo y para sî" (p. 71). Orden ascendente, definición de la condición humana, el juego de la tragedia se define entre el deber y poder, contradictoria compatibilidad: libertad y necesidad, su clave y la del texto. La lectura se enriquece con la adición de lo plural, estímulo para la inteligencia (Proust, 2012: 95).

Contextos, sociedad, cultura, función exponencial, en cada nueva lectura una emergencia de nuevos significados, transmutación de contenidos. El texto adquiere vida 
propia con la complicidad del lector-actor. El libro como sujeto. La relectura. Sklovski: "A la vejez le gusta releer. Se acaba la vejez" (1975: 52) "[...] la muerte no sabe disculparse. " (p. 17). Los libros leídos en la infancia pueden ser releídos anualmente, esto es lo que escribe Trilling (1971) sobre Huckleberry Finn, de Mark Twain “... por siempre jamás, y cada año hallarlo tan fresco como el año anterior y sólo cambiado en la medida de haberse engrandecido un poco. [...] es como plantar un retoño: cada año agrega un nuevo anillo de corteza al crecimiento de su significado. [...] Pocos son los otros libros que podemos conocer tan temprano y amar por tanto tiempo". (p. 125)

Es una exploración de nuevos confines, pero siempre revelada en la novedad. Según Barthes, el libro que no sostiene al lector, imperativo de su esencia, es texto murmullo, espuma del lenguaje, texto frígido, desmembramiento del amor, divorcio. El libro cerrado no sugiere, es letra muerta, confirmación de los antiguos. El libro abierto implica alimento para la memoria, dime cuánto lees y te diré qué eres, acondicionamiento físico mental.

Con la lectura, el libro cambia (recurrencia de Borges), las palabras adquieren otros significados, carga de pasado, experiencia. Es argumento para disentir, para la corrección, para la rebelión. Fundamento de la acción.

\section{Contextos}

Uno. A una pulpería, en la vasta ruralidad de la década de 1960, en un pueblo enclavado en las serranías, al pie de la Fila Costeña, allá por el sur, en una Costa Rica con menos de un millón de habitantes, llegó, por alguna casualidad, aventura, huida, un dependiente, acepción jurídica aceptada como parte del lenguaje coloquial en el habla popular, con implicaciones legales. Letrado, pintor; origen: Cartago. Entre los sacos de azúcar, las estibas de dulce y las bodegas de granos, las botellas de refrescos gasificados Corrales, zarzaparrillas, colas, limonadas, naturales, algo así como los hijos extraños a la unión legal. La refrigeración no existía, igual la televisión, desconocimiento del hielo. " Dentro solo había un bloque transparente, con infinitas agujas internas en las cuales se despedazaba en estrellas de colores la claridad del crepúsculo (García Márquez, 2007: 27).

Igual la televisión. En cambio, eran parte de la cotidianeidad los pleitos de Torcido y Pierna Linda, juez de paz, bocetos del paraíso y del pecado original, los amores perdidos, la

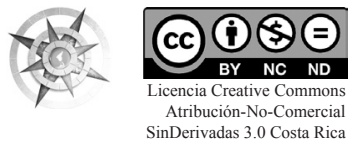

Del libro y de los vericuetos de la lectura 137 José Luis Díaz-Naranjo 
cazadora de un solo itinerario, los tarros de guaro y las cervezas Doral, con un lema publicitario posible, "las que te refrescan", entre otras muchas cosas. El dependiente habitaba en este medio además de unos cuantos libros.

Dos. Mi padre, compañero de Ángel, Chiche, Severo, Manuel, entre otros vecinos de la comunidad, estudiantes vespertinos de la escuela primaria para adultos. Su cuaderno escolar era llamado, en esas fechas, de vida, uno solo para todas las materias, almacenado en el caballete de unas de esas casas, con estructura arquitectónica, propia del trabajo de carpintería en madera, con imbricados cortes en la fachada, que hacía las veces de bodega, también de estantería, fue requisado por nosotros, su progenie. Con su caligrafía dibujó el estudiante que aprendía a leer y escribir, trazos de la materia básica para un alumno de tercer grado, útiles acarreados en un bolso, al igual que otras muchas prendas de vestir, desde uniformes deportivos con el emblema de marca de "Más Pan" en las sentaderas, hasta trajes de primera comunión, hechos con la manta de un saco de harina de trigo. Los había también "Tres Espigas". La costurera, Carmen, se solazaba en la faena de cumplir con los encargos de ropa, como olvido temporal a la violencia personificada en su marido, Roque Torcido. Con cortes y puntadas, los hacía en su vieja máquina de coser, sin pedal, a la luz de la mecha de tela mojada en tarro de querosén, el candil, la canfinera, como fuente de luz.

Y en su preocupación por aprender, mi padre, en su visita a Nashville, Tennessee, lugar de mi residencia temporal en mis días de estudiante en el extranjero pidió consejo: "- ¿Usted cree que yo leyendo pueda aprender inglés?" "-Puede ser", fue mi respuesta. "- iQué le gustaría leer?" "-Como me sé muchos cuentos tal vez con uno de ellos en inglés aprenda". Nos marchamos a una librería en los contornos de la ciudad. Ojeamos unos cuantos libros de cuentos y sobre ellos se decidió: "-por el dibujo, este parece el Gato Con Botas", me dijo. Puss in Boots. A mi regreso, interrogué sobre el resultado: "-Qué va, no entendí nada", fue su respuesta lacónica, con un dejo de frustración.

Del cuaderno de vida, desgarrábamos las hojas, con las operaciones básicas, los dictados, los abecedarios, las nociones de geografía, los dibujos coloreados de los planetas. Ahí estaba la primera presentación de la Vía Láctea, en todo su esplendor, las explicaciones para cada uno de sus componentes, de acuerdo con su posición en el sistema solar, más allá 
de la cotidianeidad del avistamiento de estrellas, en esas noches oscuras y despejadas, por la ausencia de alumbrado público, desde el inicio de la penumbra, cuando el sol se ahogaba en el mar. Los Ojitos de Santa Lucía, las Siete Cabritas, la Cruz del Sur más en la madrugada, el Arado. Ese misterio infinito, tal vez reproducido en los sueños, el vuelo hacia el firmamento y poder tocar aunque fuese el rabo de una estrella, no la cornamenta, pues esta hasta puede crear heridas.

Ese fue mi primer encuentro con la palabra escrita. El cuaderno de vida, los pocos libros, vedados y, los bultos de periódicos, amarillentos, noticias viejas, con abundante pulverización, usados tanto para la envoltura de una libra de sal, un taco de jabón de chancho o un trasto. Mi deleite supremo, repintar las letras de los periódicos colocados en el mostrador, para el uso frecuente, con los lápices usados para hacer las cuentas de los clientes: dos reales de sal, seis reales de manteca, ocho reales por una yarda de charmelina, tres pesos de abono al radio Philips, dos reales de elástico, seis reales de cerveza en dos: Beto y Rafael, hermanados, un vaso de casco para cada uno, compartían la bebida espirituosa, amarga, caliente y espumosa, luego de varios convites, al calor, no faltaría un ¡Viva Pepe Figueres! y la réplica inmediata, ¡Calderón Guardia! Pretexto simple, cargado con gran emotividad, para iniciar la pelea. La contienda militar del 48 giraba pesadamente en el imaginario colectivo, los recuerdos afloraban con vivencia y nitidez, parecía que el tiempo pasado era cosa de unos pocos días, casi horas. Parecía ayer.

Interminable lista de menudos que al final sumaría lo "mercado". Es tanto Ricardo Taza de Caldo, me debe esto Evelio Chompipa, págueme las cervezas Nino Zorra y usted Marvin Culeca deje de andar hurgando en la vecindad a esas horas de la noche. Los tendederos de ropa no podían amanecer si no eran registrados, en alianza con Bichillo, en busca de las prendas femeninas íntimas. Un día de tantos, le va a ir mal.

Con este bagaje y las repintadas de letras, con el dependiente como maestro, la lectura fue cosa de un dos por tres. Al poco tiempo se estableció la ventaja. La niña Anita, llegada de más allá del Cerro de la Muerte, lugar que con solo mencionarlo producía escalofríos y ponía la piel de gallina, se despreocupó. Otros sufrían. Bety, compañera de grado, quería agradar, ella era ruda, decían que porque comía mucha sal; del potrero de Ventura, en los recreos interminables,

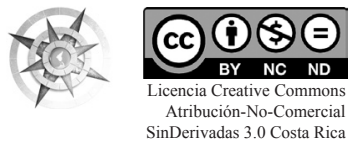

Del libro y de los vericuetos de la lectura 139 José Luis Díaz-Naranjo 
bajando por la ladera hasta el fondo de la pendiente, con el riachuelo como límite, traía a la maestra frutos de colpachí (Croton niveus). Esta última, displicente devolvía con generosidad la cortesía, reboleaba, casi jugando al tiro al blanco, en el cuerpo terroso de la niña, los presentes. La letra con sangre entra. Otros maestros lanzaban el borrador y la tiza de carbonato de calcio en contra de los pupilos y las pupilas.

Y en las vacaciones, con las llaves de la escuela en la mano, cruzando por los potreros para abreviar el camino, no había rótulo alguno con la inscripción de perro bravo o ley del merodeo, nunca nadie fue agredido por llevarse un racimo de banano o unas cuantas frutas, de por sí eran para los chanchos, me fugaba a la escuela.

Mi tata era el presidente de la Junta de Educación, por tanto depositario del ábrete sésamo, un manojo de llaves herrumbrosas a simple vista iguales. Las tardes, una vez cumplidas las tareas asignadas de trabajo doméstico, se hacían cortas en medio de una pila de libros inmensa, más de medio metro, sin anaquel, en desorden, sin mueble, en una esquina de cualquier aula y con una infinidad de Ulises en la Isla de los Cíclopes, un tanto de lagartos montubios, temerosos mares de los sargazos, muchas vueltas al día en ochenta mundos, como una clara alusión de un Julio a otro, de Cortázar (1984) a Verne. Aparte de relatos, las Veinte mil leguas de viaje submarino, la primera novela de aventuras que cayó en mis manos, regalo a un tío de su maestro, lo obtuve como préstamo. Quizá no la devolví. Señuelo tramposo, fuente de maldición, muchas veces no he recibido el retorno de los libros prestados. Castigo por ese pecado infantil.

Se abrían las páginas raídas, amarillentas, desteñidas y los personajes, paisajes, animales, aguas, todo salía en carrera alocada hacia la imaginación. El haber recogido el centavo que pateaba en la playa, mientras esperaba a la cigüeña, pudo haber salvado a los isleños de la inmersión. Pudo más la pereza de ese niño que se deleitó jugando con la monedita. Poca cosa. Cuando el ave llegó para el viaje, la isla estaba a punto de emerger, la playa para el abordaje, borrada. Una vez en la ínsula, sus habitantes ofrecían, con súplica angustiante, todo por una moneda, por pequeña que fuese, su salvación, ahora la espera será por otros cien años. Preludio de la modernidad mercadotécnica.

El tiempo voló y también el dependiente. Nunca más regresó, dejó un libro, de poemas, eso sí con dedicatoria y todo. Subrayó el poema,

140 Del libro y de los vericuetos de la lectura José Luis Díaz-Naranjo

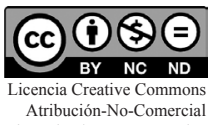


Cuando ya me haya ido, con una dedicatoria, para... los puntos suspensivos el misterio por el nombre de mujer no consignado. El rumor, "La miseria escondida en ese cuerpo siniestro, / hasta ayer recorrido por el rumor de la glorial y ahora pisado y abandonado por las hormigas del desprecio,/ aumenta sus gemidos pues la noche se extiende.". Lezama Lima (1985: 43). Enemigo rumor.

Yo el depositario, pero un depositario confiado y descuidado. Me fui y dejé el libro, con la compañía de otros pocos, en el viejo baúl desvencijado del bisabuelo materno, Ñor José, hecho con cedro amargo y acarreado a hombro desde afuera, más allá de la cordillera, cuando la decisión se consumó, viajar al General. Dicen que los viajantes gritaban en la madrugada, con eco resonante en las montañas del Valle Central, vamos pal General, vamos pal General, como despedida de la vecindad, colonos en la búsqueda de nuevos horizontes. Todo quedó en manos del cuidador de la finca. Y a esa hora de la madrugada, Vin Diente de Caca, en medio del torbellino de gallinas revoloteando, chanchos, perros y gatos, gritaba: "prendan el fuego, échenle papel". El libro de poemas fue el primero en arder, como con juguete nuevo, el fuego devoró todo. Los libros, dice Sklovski (1975: 35) arden mal, además de la mucha ceniza que producen.

El lugar cambió. Una escuela unidocente en la costa pacífica del sur, un maestro aficionado a la lectura de novelas de vaqueros. Hoy tenemos dictado. Saquen el cuaderno y el lápiz. Listos. El forastero coma aún oloroso a sudor coma con espuelas relucientes entró al Salón y preguntó coma con un tono de golpe coma por Ojo Blanco punto Casi todos los hombres salieron punto.

Un presagio se posó en la mente de todos los vaqueros coma en el ambiente se respiraba un olor a muerte punto No puedo recordar los títulos de las lecturas cargadas de whisky, polvaredas, encajes, aridez, balas, colts 45, remingtons, caballos, cuatreros, asalta bancos, galopes interminables con persecuciones, como escenario, colgados, no al estilo de Bierce (1946: 571) de su fábula fantástica The Returned Californian; San Pedro anota en el control de muertos, con la llegada de un nuevo ahorcado, buenas nuevas California ha sido civilizada. Mientras tanto la imperiosa necesidad de domar el potro, el sombrero de ala ancha, la soga atada a la silla de montar, los juegos, casi peligrosos, en medio de la plaza del pueblo, los forajidos perseguidos y los amagos de ahorcamiento. Pistolas

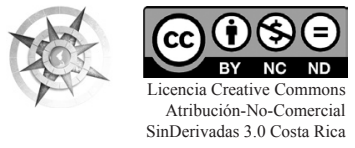

Del libro y de los vericuetos de la lectura 141 José Luis Díaz-Naranjo 
de madera, al cinto, para todos los gustos. Arte brusco.

Y del libro de poemas, si quedaron por algún tiempo blanqueando las letras impresas. Eso lo salvó del olvido. Después desapareció la prueba material. Ni siquiera el nombre de la autora, porque estoy seguro de que fue una mujer quien lo escribió, si no iquién haría posible que la luna entrase a jugar en la habitación y cansada de tanta luz se retirase, calladamente, por la ventana? Los papelitos hablan, dicen los que hacen la historia, también como prueba incriminatoria, la policía.

La afición se despertó. Luego, mucho más adelante, siguió:

En un lugar de la Mancha, de cuyo nombre no quiero acordarme, no ha mucho que vivía un hidalgo de los de lanza en astillero, adarga antigua, rocín flaco y galgo corredor. Una olla de algo más vaca que carnero, salpicón las noches, duelos y quebrantos los sábados, lentejas los viernes, algún palomino de añadidura los domingos, consumían las tres partes de la hacienda. (Cervantes, 2004: 27 )

Nostalgia, alegría, tristeza, conmiseración, todas expresiones del ser humano. Cervantes, El Manco de Lepanto sigue inspirándonos.
Pero no dejemos el humor lacerante, ácido, amargo, negro, demoledor, contagioso, en una cultura, que, resultado de los desvaríos de la sociedad, el libro sirve, entre otros muchos posibles usos, de relleno en las bibliotecas de los estudios de televisión. En esa cultura oficial, ¿organizacional acaso?, el defecto es lo risible. Destino final, el Pelirrojo de de su relato Agenda azul No. 10 ( Jarms y Vendesky, 1971) se impone como una máxima:

Había una vez un Pelirrojo que no tenía ojos ni tenía orejas. Tampoco tenía pelo, de modo que llamarlo pelirrojo era solo una forma de decir. No podía hablar, porque no tenía boca, tampoco tenía nariz. Ni siquiera tenía brazos o piernas. No tenía estómago, ni espalda, ni espina dorsal, tampoco tenía otras entrañas. No tenía nada. De modo que es difícil entender de quién estamos hablando. Será mejor entonces que no hablemos más de él (p. 34).

\section{Sociedad}

Una cuesta empecinada, paredones a un lado, al otro, despeñaderos, con la tierra de un color rojizo, llevaban al visitante, una vez en la cúspide, a una meseta, con la quebrada atravesando el caserío. De seguro que el dependiente hizo este recorrido, 
cuando por algún designio llegó a este pueblo olvidado. La cazadora bufaba al subir la cuesta de Los Reyes, pasando por enfrente de las casas de Esposoria, en la vuelta, Tingo, la sobadora, Cleta, acarreando cabezas y patas de vaca, de la carnicería quincenal, para la sopa de la parentela, festín, Ña Nina, con los rezos a granel, Nono Prado, Pepe, peleador empedernido, Mel el de aquí va Mel Melcocha para el que se lo quiera comer, alardeando de los alcoholes ingeridos y de la comida a la espera, "[...] que pereza comer huevo", Toreano, el del perreque, a pesar de las imperativas órdenes del consorte, la mujer con rubor siempre se negó ante el mandato de mostrar. Nino, con el pago de dos pesos, recompensa por encontrar la plancha de dientes y su brillo dorado, dejada tirada en la última borrachera, ahora cubierta de tierra por las hormigas intrépidas en búsqueda de manjares, otros con la mofa impertinente ante el sufrimiento ajeno: por ahí pasó un perro muy sonriente, iba estrenando dientes de oro, hasta llegar a lo alto.

Pocas casas, tantas como para que el maestro de escuela en sus ratos de ocio, pudiese imaginar y realizar un mapa. Los nombres, los lugares, los cerros, los bajillos, las quebradas, las tranqueras, los trapiches, la pulpería, la escuela, la ermita, la saca de guaro, todo registrado cartográficamente. Cada familia con su ubicación precisa, coloreada para una mayor distinción. El número exacto de habitantes, así como de alumnos, con cada nuevo alumbramiento, la adicción al listado de pobladores, Juana Blanco, la partera, informaba. En las mañanas, grupos campesinos desplazándose a los lugares de trabajo agrícola, sobresalían los Navarro, los Aquilinos, los Leiva, los Acuña. Algunos años después, no los suficientes, los Burumbún. Estos en franca algarabía con risotadas, gritería, chistes, bromas y madrazos, se movilizaban en bicicletas.

La civilización había llegado, la gran compañía ofrecía trabajo, el monocultivo como gran atractivo. El radio Philips, sintonizado en la emisora local, transmitía, la voz del locutor forzada guturalmente para mayor gravedad, anunciaba con insistencia, "se necesitan trabajadores de campo para desempeñarse en la producción en la empresa tal", hasta el nombre era un imán. Tiempos de cambio.

Los escándalos no traspasaban la quebrada, cerro, fila, límite entre caseríos. Carlos Cafetera matoneó escondido en un cafeto a un hombre --cuestión de celos-- le robaba el amor de su mujer, "le robaba pasto". De un plomazo lo dio por muerto y

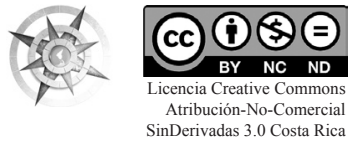

Del libro y de los vericuetos de la lectura 143 José Luis Díaz-Naranjo 
así fue. Antes había, con otro compinche, su hermanillo, asaltado la casa de Lito, el más millonario de los millonarios. Fue él, Lito, quien financió la construcción del hotel más grande de la ciudad. Desde lo alto, los vecinos trataban de visualizarlo en la lejanía, tal era su majestuosidad: i-véanlo, véanlo-!, gritaban. No sacaron nada. Como venganza, en esa madrugada, se llevaron un pantalón de trabajo, bastante viejo, que tenía Lito colgado de un clavo de tres pulgadas en el cuarto y lo dejaron botado en el potrero. Al día siguiente, la hija, Tina, buscó la prenda y la encontró. Hurgó en los bolsillos. Guardados estaban treinta mil colones. Mucha plata para entonces. ¿Qué ilusiones se armaron! Con un sueldo como jornalero de tres pesos al día, qué festín, todos con la ilusión de no haber sido los primeros en buscar. Al unísono el mismo lamento.

De los clavadores para el zinc pegados a las cerchas, cuando Lito arrancó la casa vieja para hacer una nueva, también de madera, caían billetes de cinco que él guardaba con recelo en su pantalón. Esa era la caja fuerte. Ninguno de los peones podía echar mano a esa platilla. En esos días, Lito decía "¡no se vayan! hoy hay café con pan", "ni que nos estuviéramos muriendo de hambre". Nino Zorra fue testigo. Carlos Cafetera murió en la cárcel, dicen que con una gran tristeza. Aficionado, como era, siempre anduvo armando grupos musicales, legado a las lomas en las que distribuían las casas, bullaranguería en los turnos y martirio en los ensayos: $\mathrm{Vi}$ cente Perra Chinga desafinaba, Edwin Sapa cantaba mal y Tista siempre con su acordeón; herencia musical, luego vendrían más músicos.

Emilce, esa cotonuda, poca pena, parió en el cafetal, dejó botado al recién nacido, producto de la sabandijería, se metió con un hombre casado el viernes santo, iqué barbaridad!, la abuela, Balvina lo recogió, picoteado por las malditas gallinas y con pequeñas ampollas de los aguijones de las hormigas. Le dio un dudoso cariño y amor de abuela. Ella quería su muerte: el escándalo social era insoportable. Años después la madre real fingió el papel de hermana mayor, lo protegió y cuidó con esmero y ternura. El hijo abandonado halagaba el trato.

\section{Cultura}

Llegó al pueblo un saxofonista hasta con el saxofón, instrumento extrañísimo en la unidad constituida por las maracas, la guitarra, el güiro y el acordeón. Contratado por Carlos Cafetera, para su conjunto musical, 
ofreció cursos sobre cómo aprender a tocar este instrumento. Había que desplazarse una jornada larga por trochas, veredas, trillos, atajos, para asistir a las clases. Todo funcionó no más allá de un par de meses. El maestro de música se montó en la carreta, empinó el codo, celebró como los grandes al dios Baco, lloró por el despecho, por el destierro, por los amores idos, por los no encontrados. En las tardes la radio transmitía dramas, romances, aventuras, con cambio de voces del locutor o locutores interpretando a los personajes, sonidos y música de fondo, una descripción certera de los paisajes y las situaciones, siempre la lucha por la justicia o el desamor, también había persecuciones. No podía faltar la congregación, como centro, este aparato. En las escuelas, con cada festividad oficial, los cuadros ${ }^{1}$, El Dolor de Muelas, Mercando Leña, La Milpa, La Tule, El Cadejos. Alborozo y la alegría.

Y con Oliverio Girondo, (1999), solo la muerte era ineludible. ¡Ah, la muerte! El panteón, la tierra arcillosa, con cepas de pasto que se han encargado de borrar el espacio de la memoria. Las cruces de madera, podridas algunas, otras perdidas

1 N.de E. Los cuadros eran representaciones artísticas de la niñez escolar, con motivo de celebración de efemérides. de su ubicación original, los deudos buscando, con medida de pasos, los posibles sitios de las sepulturas, debe de estar por aquí decían, y sin más, tiraban unas cuantas flores según la ocasión, día de difuntos, aniversarios, cumpleaños, o simplemente remordimientos, el finado sufría de abandono familiar. Un triste cementerio en lo alto de la topografía, lugar, malsana práctica de irrespeto a la parca, de pastoreo para algunos de los animales de los pobladores que, por alguna razón, se mantiene más verde que en el resto de los predios. Lugar también de sustos.

Un día a un medio loco se le ocurrió hacer del cementerio su casa y guarida, la pequeña capilla desvencijada, de madera, un altar entablillado, piso de tierra, era su habitación, también la caballeriza. Como estaba deschavetado, salía, montado en su corcel negro como el carbón, rayando la media noche, a dar un paseo sobre toda la fila, especialmente en noches de luna nueva, la oscuridad cómplice, con un escándalo infernal, dicen que amarraba latas a la cola de la bestia, con el trote de esta el ruido aumentaba. Ni los más osados se atrevían a caminar durante esas horas por ese paraje. El rumor se esparció con la ventolera del lugar: ¡ahí asustan! Eso disminuyó en los caseríos los hábitos nocturnos de sus pobladores; las

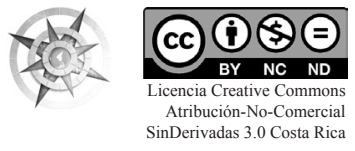

Del libro y de los vericuetos de la lectura 145 José Luis Díaz-Naranjo 
andanzas se aplacaron, y aumentó el número de embarazos.

\section{Función exponencial}

La obra se dibuja con los trazos del grafito sobre el papel, resultado de un simple juego: Hegel (1979): “... las obras de arte son productos accidentales de este juego." (p 67). Ocupación a que nada nos obliga, libertad de interrumpir, la tensión en la cuerda del arco. "Los libros se escriben durante décadas" (Sklovski, 1975: 15). Viaje a lo cotidiano, a lo desconocido. Con la lectura, seguimos: "[...] hace falta tiempo para leer un libro, para esperar el final, para sentir emoción." (p. 14). La velocidad, principal enemiga, compañera inseparable del maniqueísmo publicitario, mundo de la mercancía, cada nuevo día una nueva posibilidad de embaucar sobre la base de una supuesta transacción con beneficios para ambas partes, el libro como objeto de los mercachifles. El lector, así lo exige Aguilera Garramuño (2010), debe "[...] ser atento, dispuesto a releer [...]” (p 99). Además la lectura, confesión absoluta de Hesse (1978) si no es con amor "[...] es uno de los pecados contra el espíritu" (p. 83). La lectura como incitación (Proust, 2012), "[...] la lectura es una amistad [...] En la lectura, la amistad a veces recupera su pureza original. Con los libros no hay amabilidad. Estos amigos, si pasamos la velada con ellos, es porque realmente nos apetece." (p. 92). Los juegos del silencio.

\section{De nuevo Pessoa (1984):}

\begin{abstract}
Nunca he podido leer un libro entregándome a él; siempre, a cada paso, el comentario de la inteligencia o de la imaginación me ha interrumpido la secuencia de su propia narrativa. Después de unos minutos, quien escribía era yo, y lo que estaba escrito no estaba en ninguna parte. (p. 41)
\end{abstract}

Una industria inmensa con la característica de producir una mercancía que debe flotar. Y sobre la liviandad, "La facilidad de la lectura es la norma en las letras desde que comenzó el reinado de la prisa general y de las hojas impresas que impulsan $u$ hostigan ese movimiento. Todo el mundo tiende a no leer más que aquello que todo el mundo podría escribir." "[... ] no pidáis el esfuerzo, no invoquéis la voluntad: aquí triunfa la creencia, acaso ingenua, de que el placer y el esfuerzo se excluyen. Confieso por lo que a mi toca, que no capto nada en un libro que no se me resiste". (Valery, 1961: 114-115)

La ilusión visual sin exigencias mayores: los sentidos se atrofian, una cosa a la vez, o tacto u olfato, o sonido o vista, o gusto. Uno factorial como expresión de las emociones, no cinco.

146 Del libro y de los vericuetos de la lectura José Luis Díaz-Naranjo
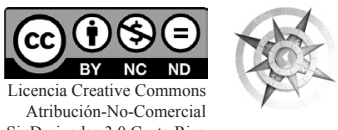
El mercado delega la escritura así también delega la lectura, Chartier (2000) lo expone como un problema fundamental de la sociedad: la mediación. Todo viene digerido, con la dosis exacta de lo que se quiere. Lo importante es la venta o por oposición, como afirmación, la compra. Con Marx (1979): realización de la mercancía " ... que parece ser una cosa trivial, de comprensión inmediata. Su análisis demuestra que es un objeto endemoniado, rica en sutilezas metafísicas y reticencias teológicas" (p. 87).

La lectura invoca. Otra vez Borges, a quién Savater (1998) lo ha descrito como:

“[...] el raro encanto de un aventurero que ha explorado las bibliotecas con el ingenuo arrojo y curtida astucia con la que otros han frecuentado las selvas, los mares, los enredos políticos, las batallas o los hechos de amor. Y que desde los libros, con desesperada nostalgia y lucidez, habla de mares y selvas, de la muerte en la guerra y de la agonía enamorada. Pocos escritores exigen tanta complicidad en el lector como Borges: ninguno le recompensa mejor cuando se la concede" ( $\mathrm{p}$. 223-224).

La lectura reúne a los opositores, es un ejercicio de tolerancia. El libro arma. Con Drieu La Rochelle
(2006), podemos afirmar que no se ha dicho nada de la fuerza de la pluma en contra del cañón. El consumo aniquila; el peor de los actos de violencia, los centros comerciales, lugares de entrenamiento terrorista. Una sociedad desfachatada, gobernada por el general Orangu, con sus habitantes "[...] dichosos a partir del día en que tienen la sangre llena de pescaditos de oro." (Cortázar, 2011, p 61). Carga de cinismo propia de quienes auspician y promueven la ignorancia, cultura tranquilizante, (Bauman, 2013), "[...]depósito de productos conservantes." (p 16). Con Sollers (1978): "[... instancia necesaria de la represión [...] alinear y apagar" (p 6), en manos de la burocracia, del publicista, de los estabilizadores, del comerciante, del político de profesión. Creadores de "[...] valores efímeros pero rentables, agitan las aguas que salpican a quienes mantienen aún los ojos abiertos y ensordecen a todos con su griterío." (Goytisolo, 2006, p 19).

Hace unos años, las televisoras anunciaron, con serpentinas multicolores y fuegos artificiales, con maratónicas discusiones monotemáticas, su cierre, durante pinche y desmesurada ridícula hora, protesta como respuesta a la ausencia de libertad de expresión en un país sudamericano. Habría sido lindo lo contrario: transmisión solo por una

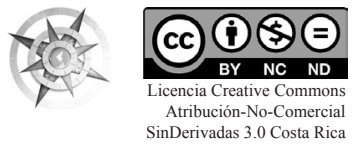


hora al día y tal vez en la madrugada. El resto, silencio.

En la ópera bufa, el trabajo como adoración, es sagrado. Doble vía, trabajo traducido en ganancia, explotación; trabajo traducido en consumo, adicción. Trabajar, trabajar para engrandecer la riqueza social y las miserias individuales. "[...], trabajad, trabajad para que, haciéndoos cada vez más pobres, tengáis más razones para trabajar y ser miserables". (Lafargue, 1970: p. 23) Esta es la proclama del yerno anarquista de Karl Marx. Con Nicanor Parra: "Para ganar un pan imperdonablel duro como la cara del burgués/ con olor y sabor a sangre". (1966: p. 78)

¿Y el ocio? ¿Cómo leer, si esta vida modelada por el sistema sustentado en las exigencias de la falaz modernidad, nos aniquila? Paul Lafargue (1970) redefine las funciones en un régimen de pereza:

\section{"[...] con espectáculos y representa-} ciones teatrales perpetuamente: será la ocupación más adecuada para nuestros burgueses legisladores [...]". (p. 46). Todo empezará con el "[...] entremés titulado Farsa Electoral [.... . Seguidamente se iniciará la representación de la gran obra El robo de los bienes de la nación". (p. 47). Mientras tanto el “... ciudadano de ninguna parte...", declaración de Monterroso (1993), quien agrega sobre su experiencia de exiliado: "Vivo con la incertidumbre de mi derecho a pisar ni siquiera los treinta y cinco centímetros de planeta en que me paro cada mañana" (p. 66-67) Ciudadano pequeño burgués, que en los fundamentos de su miseria, al decir de Bourdieu (2001: 207), con la creencia de que defiende principios elevados, construye su propia desdicha, al resistirse, por cualquier medio, a la asfixia y destrucción de su supuesta prosperidad, pensando en no morir de frío y hambre, inanición. Asume con compulsiva conducta la laboriosa intensidad del trabajo a destajo. La pobreza es sumamente complicada. Orwell (1973) lo expresa con suficiente fuerza:

Resulta que uno ha pensado mucho en la pobreza, algo que uno ha temido durante toda su vida, algo que uno sabe que le ocurrirá tarde o temprano, y luego resulta que es total y prosaicamente diferente. Uno pensaba que sería muy sencilla, y es extraordinariamente complicada. Uno pensaba que sería terrible, y es simplemente mezquina y aburrida. Lo primero que uno descubre es esa ruindad esencial de la pobreza; los expedientes a los que obliga, su complicada mezquindad, el tener que ir arañando de un sitio a otro. (p. 19) 
Más adelante, da la estocada final:

Porque cuando uno se acerca a la pobreza, descubre algo que supera a todos los demás descubrimientos. Uno descubre el aburrimiento, las pequeñas complicaciones y el principio del hambre, pero también descubre las grandes características redentoras de la pobreza: el hecho de que aniquila el futuro (p. 22).

Principio matemático de simplificación: "Descubres que un hombre que ha pasado una semana sólo a base de pan y margarina, no es ya un hombre, sino un estómago con algunos órganos accesorios". (p. 21)

Así, la lectura continúa a la espera, también los viajes, "[...] cuando uno lee, siempre le gusta salirse un poco de sí mismo, viajar" (Proust, p. 97). La televisión, las revistas, los periódicos, la farándula, nos llenan la esperanza de falsas promesas, principio de la delegación, estrategia de la complacencia.

De la Boétie, amigo de Montaigne (2014: p. 214),: "Escribiólo el autor por vía del ensayo antes de alcanzar los dieciocho años de edad, en honor de la libertad y contra los tiranos", lo expuso en el Discurso sobre la servidumbre voluntaria (...) presumiblemente en 1548, las fechas precisas no interesan:
No piensen que hay pájaro alguno que se capture con artimañas, ni pez alguno que, por la golosina de gusano, se enganche más pronto al anzuelo que todos los pueblos que se engolosinan rápidamente con la servidumbre a la menor dulzura que se les pase, como se dice, delante de la boca. Es una cosa maravillosa que se dejen llevar tan prestos solamente con que se les adule. Los teatros, los juegos, las farsas, los espectáculos, los gladiadores, las bestias exóticas, las medallas, los cuadros y otras drogas semejantes, eran para los pueblos antiguos los cebos de la servidumbre, el precio de la libertad, los instrumentos de la tiranía. (2006:p. 35)

Modorra de la modernidad. Como la dedicación a lectura no es la excepción, bien vale recordar el consejo del malogrado, Cohn-Bendit, Daniel el Rojo (1969), en las jornadas francesas de mayo-junio 1968:

Contempla las imágenes que danzan ante tus ojos, contempla a los actores que simulan representar lo que tú vives diariamente, sin que por desgracia, lo consigan. Luego, en el mismo instante en que el primer anuncio aparezca en la pantalla, coge unos cuantos tomates iy a la obra! Coge unos cuantos huevos ¡y a la obra! Recházalo todo. Luego sal a la calle, desgarra todos los anuncios [...] (p. 323) 
El poder transmuta los criticados errores del pasado en aplaudidas virtudes del presente. La rebelión es un buen negocio; el Che Guevara, estampado en prendas de vestir, llaveros, viseras, objetos símbolo de modernidad, deambula como mercancía, en los espacios del mercado.

Sigamos el consejo de Jacques Prevert (1979) con su poema El Tiempo Perdido:

Ante la puerta de la fábrica
el obrero se detiene de repente
el buen tiempo ha tironeado de su
chaqueta
y no bien se vuelve y mira al sol
muy rojo muy redondosonriente en
su cielo de plomo
le hace guiños
familiarmente
Di camarada sol
¿no te parece
una reverenda burrada
regalarle un día como este
al patrón? (p. 74)

Dediquemos ese tiempo desperdiciado a la lectura. La biblioteca como paraíso.

\section{Nota final}

Años después y del tiempo presente, un año atrás, en una feria local de libros encontré una segunda edición del poemario El aire, el agua y el árbol de Victoria Garrón de Doryan, publicado por la Editorial Costa Rica en 1998. Para la fecha del reencuentro con el texto en mención, el cuerpo de este pequeño esbozo sobre libros y lecturas estaba casi concluido, solo quedaban las recurrencias de siempre en los adicionamientos o supresiones, la revisión cíclica como virtud necesaria, los escritos necesitan el adobo con una buena sazón de paciencia y constancia o añejamiento en los odres del tiempo, de buenas a primeras tendrán algunas virtudes, pero sobre todo muchos defectos. Por ello mismo me he obligado a incluir esta nota. Qué deberá entenderse como explicativa de esa pasión iniciada en la niñez y que se empeña en continuar con proyectos de lectura, aún cuando exista una buena estiba de últimas adquisiciones, pero sobre todo, los compromisos de las relecturas.

Los ejemplares expuestos en los muestrarios de metal en esa actividad comercial, los prefiero de olorosa madera, eran considerados como inventarios en bodega, que en ese momento era importante descartar como parte de los activos de la editorial; el material no vendido, eso de las mercancías no realizadas, se transforma en un obstáculo y referente para la calificación administrativa con conceptos negativos y críticos de la gestión financiera. 
Los cuatro ejemplares en existencia los adquirí y con ello logré de nuevo revivir mi encuentro con este poemario, a la edad de cinco o seis años. Este fue el primer libro leído, regalo de Édgar Loaiza Granados, recibido, probablemente, cercano a la fecha de su publicación, a un año de iniciar el proceso formal en el sistema de la educación escolar. La primera edición es de 1962 con prólogo de Isaac Felipe Azofeifa, titulado "Teoría para un libro de poemas", volumen inaugural de "Poetas nuevos de Costa Rica", con la participación de Lilia Ramos, Isaac Felipe Azofeifa y Francisco Amighetti como selectores de los trabajos por divulgar en la naciente colección.

El poema que más me hacía volar la imaginación se llama Juguete

La luna anoche llegó a mi cuarto, jugó a los toros con el reloj, tocó el ropero, besó la silla, mordió la mesa y el tocador. La luna anoche llegó callada, pasó la verja y el comedor, de puntillas llegó a mi cama y con sus rayos me despertó. ¿Luna malilla! ¿Qué te propones? :Quieres peinarme con tu esplendoro es que pretendes limpiar la mesacon la colita de tu fulgor?Pero jya veo!

2 N.de E. Este poema, de Victoria Garrón, fue originalmente publicado en Repertorio Americano, 1947, (43) 6, 89.
¡Ya te despides! ¡Ya te cansaste de tanta luz!Y la lunita salió calladapor la puerta de mi balcón.

¿Qué puedo decir a estas alturas de la vida! Cuando la lectura se transforma en un pesado fardo y otros medios menos estimulantes o carentes de sublimidad y nobleza obstaculizan la existencia del silencio necesario, "[...] ese milagro de una comunicación dentro de la soledad [...]" (Proust, 2012). Paradojas. Muchas lecturas sobre novelas de vaqueros, cómics de la editorial mexicana Novaro, intercambiados semanalmente al lado este del parque de San Isidro de El General, frente a los cines Paulina y Fallas, otra fuente de inspiración, o en la esquina de la Tienda la Grandeza, la de los dos pisos y medio, establecimiento que además distribuía este material. Congenio con grupos sociales que ahora resultarían desclasados, en ese tiempo no: amantes de las películas mexicanas, de la lucha libre, lectores de El conejo de la suerte, Chanoc, Tarzán, Memín, La pequeña Lulú. También teníamos el encantamiento de las audiciones con las transmisiones radiales de $\mathrm{Ra}$ dio Sinaí, de cuentos de los clásicos, entre las siete y ocho de la noche.

En la misma época, ahora de colegial, aparecieron Julio Verne, José Martí, Emilio Salgari y los textos de

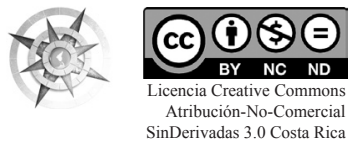

Del libro y de los vericuetos de la lectura 151 José Luis Díaz-Naranjo 
lectura y comentarios propios de los programas educativos. Las primeras lecturas políticas y la necesidad de transformar la sociedad como un todo. Algunos ya teníamos la percepción sobre las distancias y brechas sociales, bastaba comparar los tratos diferenciados dentro del régimen académico para establecer los derroteros de lucha. El año 1970 fue particularmente aleccionador, ALCOA se convirtió en la tutora que un párvulo necesita, y lo mejor con un trabajo ad honorem.

Lo demás es historia.

$$
\begin{array}{r}
\text { Abril 2013-febrero } 2018 \\
\text { jldiaz@una.cr }
\end{array}
$$

\section{Referencias bibliográficas}

Aguilera Garramuño, M.T. (2010). Poéticas y obsesiones. México: Universidad Veracruzana.

Barthes, R. (1978). El placer del texto. Segunda edición. México: Siglo XXI Editores.

Bauman, Z. (2013). La cultura en el mundo de la modernidad líquida. Primera edición en español. México: Fondo de Cultura Económica.

Bierce, A. (1946). The collected writings. Introduction by Clifton Fadiman. USA: The Ciatadel Press.

Block de Behar, L. (1984). Una retórica del silencio. Funciones del lector y procedimientos de la lectura literaria. México: Siglo XXI Editores.

Bordieu, 2001) Las estructuras sociales de la economía. Argentina: Ediciones Manantial SRL.

Borges, J.L. (1983). Borges Oral. España: Bruguera Libro Amigo.

Borges, J.L. y Sábato, E. (1982). Diálogos Borges Sábato. Grabados y compilados por Orlando Barone en diciembre de 1974. Argentina: Emecé Editores.

Bourdieu, P. (2001). Las estructuras sociales de la economía. Argentina: Ediciones Manantial SRL.

Cervantes, M. de (2004). Don Quijote de la Mancha. Tercera reimpresión. Edición del IV centenario. México: Real Academia de la Lengua Española-Asociación de Academias de la Lengua Española.

Chartier, R. (2000). Cultura escrita, literatura e historia. Conversaciones con Roger Chartier. Segunda edición. México: Fondo de Cultura Económica.

Conh Bendit, G. y Conh Bendit, D. (1969). El izquierdismo remedio a la enfermedad senil del comunismo. París mayo-junio 1968. Segunda edición. México: Grijalbo S.A.

Cortázar, J. (1984). La vuelta al día en ochenta mundos. Vol. I. Treceava edición de Bolsillo. México: Siglo XXI Editores.

Cortázar, J. (2011). Cuentos completos. Volumen 3. México: Santillana Ediciones Generales. Punto de Lectura. 
De la Boétie, E. (2006). Discurso sobre la servidumbre voluntaria. Argentina: Libros de la Araucaria.

Drieu la Rochelle, P. (1980). Prólogo, en: D.H. Lawrence, El gallo escapado. España: Leartes.

Girondo, O. (1999). Obra completa. España: ALLCA-Universidad de Costa Rica.

Goytisolo, J. (2006). Tradición y disidencia. Segunda reimpresión. México: Fondo de Cultura Económica.

Hegel, G.W.F. (1979). Introducción a la estética. España: Ediciones de Bolsillo.

Hesse, H. (1978). Lecturas para minutos. Cuarta edición. España: Alianza Editorial.

Jarms, D. y Vedensky, A. (1971). Literatura Rusa del Absurdo. Un hallazgo literario. Obras Selectas. Compilación e introducción: George Gibian. Argentina: Editorial Pleamar.

Joyce, J. (1979). Retrato del artista adolescente. México: La Nave de los Locos.

Lafargue, P. (1970). El derecho a la pereza. México: Juan Grijalbo Editor.

Lezama Lima, J. (1985). Poesía completa. Cuba: Editorial Letras Cubanas.

Manguel, A. (2013). Una historia de la lectura. Cuarta edición. España: Alianza Editorial.

Marx, K. (1979). El capital. Tomo I, Vol. 1, libro primero, el proceso de producción de capital. Octava edición. México: Siglo XXI Editores.
Montaigne, M.E. de (1984). Ensayos (I) (edición íntegra). España: Ediciones Orbis, S.A.

Monterroso, A. (1993). Los buscadores de oro. España: Editorial Anagrama. Narrativas hispánicas.

Orwell, G. (1973). Sin blanca en París y Londres. España: Ediciones Destino.

Parra, N. (1976). Antipoemas. Antología 1944-1969. España: Seix Barral.

Pessoa, F. (1984). Libro del desasosiego. Tercera edición. España: Seix Barral.

Pound, E. (1971). Sobre Joyce. Edición y comentarios de Forrest Read. España: Barral Editores.

Prevert, J. (1979). Palabras. Octava edición. Argentina: Compañía General Fabril Editora.

Proust, M. (2012). Días de lectura. México: Taurus-Prisa Ediciones.

Savater, F. (1998). Despierta y lee. México: Alfaguara.

Sklovski, V. (1975). La cuerda del arco. Sobre la disimilitud de lo símil. España: Editorial Planeta.

Sollers, Ph. (1978). La escritura y la experiencia de los límites. España: Pre-textos.

Trilling, L. (1971). La imaginación liberal. España: Edhasa S.A.

Valery, P. (1961). Política del espíritu. Argentina: Editorial Losada S. A.

Zaid, G. (1996). Los demasiados libros. México: Océano. 